
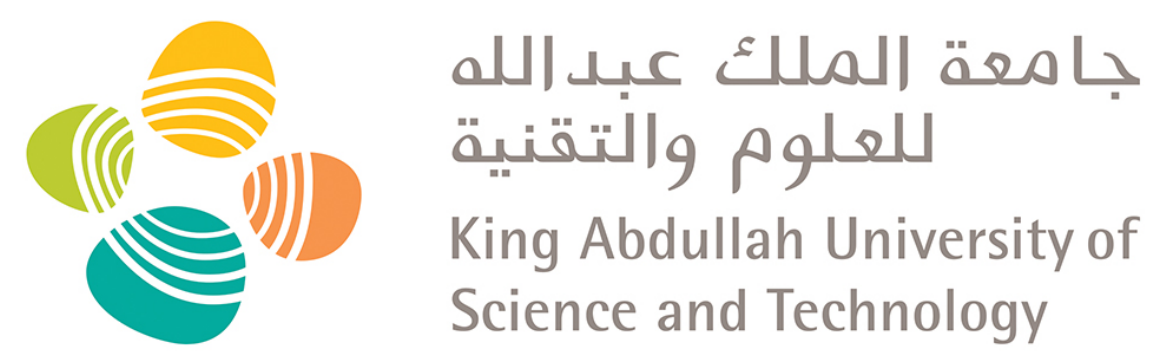

King Abdullah University of

Science and Technology

\title{
Aqueous Cathodic Deposition: Aqueously Cathodic Deposition of ZIF-8 Membranes for Superior Propylene/ Propane Separation (Adv. Funct. Mater. 7/2020)
}

\begin{tabular}{|l|l|}
\hline Item Type & Article \\
\hline Authors & $\begin{array}{l}\text { Wei, Ruicong; Chi, Heng-Yu; Li, Xiang; Lu, Dongwei; Wan, Y; Yang, } \\
\text { Chih-Wen; Lai, Zhiping }\end{array}$ \\
\hline Citation & $\begin{array}{l}\text { Wei, R., Chi, H., Li, X., Lu, D., Wan, Y., Yang, C., \& Lai, Z. (2020). } \\
\text { Aqueous Cathodic Deposition: Aqueously Cathodic Deposition of } \\
\text { ZIF-8 Membranes for Superior Propylene/Propane Separation } \\
\text { (Adv. Funct. Mater. 7/2020). Advanced Functional Materials, 30(7), } \\
\text { 2070042. doi:10.1002/adfm.202070042 }\end{array}$ \\
\hline Eprint version & Post-print \\
\hline Dol & 10.1002/adfm.202070042 \\
\hline Publisher & Wiley \\
\hline Journal & Advanced Functional Materials \\
\hline Rights & Archived with thanks to Advanced Functional Materials \\
\hline Download date & $17 / 06 / 202110: 39: 39$ \\
\hline Link to Item & http://hdl.handle.net/10754/661580 \\
\hline
\end{tabular}




\section{WILEY-VCH}

1 DOI: $10.1002 /$ ((please add manuscript number))

2 Article type: Full Paper

\section{Aqueously Cathodic Deposition of ZIF-8 membranes for Superior Propylene/propane Separation}

Ruicong Wei ${ }^{\dagger}$, Heng-Yu Chi ${ }^{\dagger}$, Xiang Li, Dongwei Lu, Yi Wan, Chih-Wen Yang, Zhiping Lai*

$\uparrow$ These authors contributed equally

Dr. R. Wei, H.-Y Chi, Dr. X. Li, Dr. D. Lu, Prof. Z. Lai

Advanced Membranes and Porous Materials Center, Division of Physical Sciences and Engineering, King Abdullah University of Science and Technology, Thuwal, 23955-6900, Saudi Arabia

E-mail: zhiping.lai@kaust.edu.sa

Y. Wan, C.-W. Yang

Physical Sciences and Engineering Division, King Abdullah University of Science and Technology, Thuwal, 23955-6900, Saudi Arabia

Keywords: aqueous, electrochemical, MOF membrane, propylene/propane separation, ZIF-8

Electrochemical deposition has emerged as a novel approach to fabricate metal-organic framework (MOF) films. Here, for the first time, an aqueously cathodic deposition (ACD) approach is developed to fabricate ZIF-8 type of MOF membranes without addition of any supporting electrolyte or modulator. The fabrication process uses $100 \%$ water as the sole solvent and a low-defect density membrane is obtained in only 60 min under room temperature without any pre-synthesis treatment. The membrane exhibites superior performance in $\mathrm{C}_{3} \mathrm{H}_{6} / \mathrm{C}_{3} \mathrm{H}_{8}$ separation with $182 \mathrm{GPU} \mathrm{C}_{3} \mathrm{H}_{6}$ permeance and 142 selectivity, making it sit at the upper bound of permeance vs. selectivity graph, outperforming majority of the published data up to 2019. Notably, this approach uses an extremely low current density $\left(0.13 \mathrm{~mA} \mathrm{~cm}{ }^{-2}\right)$ operated under an ultra-facile apparatus set-up, enabling an attractive way for environmentally friendly, energy efficient and easily scalable MOF membrane fabrications. This work demonstrates a great potential of aqueously electrochemical deposition of MOF membrane in the future research. 


\section{WILEY-VCH}

\section{1. Introduction}

3 Gas separation using membrane technology has attracted numerous attentions in the recent

4 decades due to its high separation performance, energy efficiency and attractive economic 5 feasibility. Efforts in studies on MOF-based membranes have resulted in prolific outcomes

6 owing to the material's ordered crystallized structures, high porosity and unique chemical 7 environment, which can provide either sieving effects or selective adsorption for gas 8 separations. $^{[1]}$ Among a variety of MOFs developed, ZIF-8 stands out as a promising 9 candidate for the membrane application attributed to its high thermal and chemical stability. ${ }^{\text {[2] }}$ ZIF-8 has a window size of $\sim 0.34 \mathrm{~nm}$ (Figure S1a). ${ }^{[3]}$ However, the structure flexibility allows

11 it to be used in a number of binary gas separations such as $\mathrm{H}_{2} / \mathrm{CO}_{2}, \mathrm{CO}_{2} / \mathrm{N}_{2}, \mathrm{H}_{2} / \mathrm{CH}_{4}, \mathrm{C}_{2} / \mathrm{C}_{3}$, 12 and $\mathrm{C}_{3} \mathrm{H}_{6} / \mathrm{C}_{3} \mathrm{H}_{8}$. In particular for $\mathrm{C}_{3} \mathrm{H}_{6} / \mathrm{C}_{3} \mathrm{H}_{8}$ separations, $\mathrm{C}_{3} \mathrm{H}_{6}$ and $\mathrm{C}_{3} \mathrm{H}_{8}$ have kinetic diameters of $0.40 \mathrm{~nm}$ and $0.42 \mathrm{~nm}$ respectively (Figure S1b and 1c), the slightly size difference enables $\mathrm{C}_{3} \mathrm{H}_{6}$ to diffuse through $\mathrm{ZIF}-8$ in a speed of 125 times higher than $\mathrm{C}_{3} \mathrm{H}_{8}{ }^{[4]}$ This large diffusion disparity allows for an effective $\mathrm{C}_{3} \mathrm{H}_{6} / \mathrm{C}_{3} \mathrm{H}_{8}$ separation with estimated ideal permselectivity of $130{ }^{[5]}$ Inspired by the separation potential of this material, our group has firstly demonstrated the ability of ZIF- 8 membrane for effective $\mathrm{C}_{3} \mathrm{H}_{6} / \mathrm{C}_{3} \mathrm{H}_{8}$ separation ${ }^{[6]}$ and a selectivity up to 90 was achieved after careful optimization of the activation process and defect elimination. ${ }^{[7]}$ However, improving the selectivity is always compensated by a decrease in permeance. Many novel membrane fabrication methods have been developed such as

21 substrate-seeded heteroepitaxy ( $\mathrm{SSH}$ ), spin coating techniques (SCT), liquid-phase epitaxy 22 (LPE), interfacial synthesis, bottom-up modular assembly (BMA), chemical vapor deposition 23 (CVD), and atomic layer deposition (ALD). ${ }^{[8]}$ Although separation performance has been continuously improved following the intensive efforts being contributed to this field, the same trade-off trend between the selectivity and permeance was observed. The main reason is that defects are developed randomly during the membrane process in all the above mentioned 


\section{WILEY-VCH}

1 fabrication methods. A relatively thick membrane is required to minimize defects, but thus inevitably decrease the membrane permeance.

Recently, the electrochemical deposition has emerged as a novel approach to fabricate MOF films. ${ }^{[9]}$ This approach requires relatively minor or non pre-treatment of the substrate, shorter synthesis time, and milder synthesis condition. ${ }^{[10]}$ It also allows for continuous production which acts as a major advantage compared with other methods for industrial scaleup. ${ }^{[9]}$ More importantly, this method may provide an error-correction mechanism since the deposition can be controlled by current. In general, anodic dissolution, cathodic deposition and electrophoretic deposition are the three methods being used in this approach for the fabrication. For anodic dissolution, a metal plate is used as anode and the metal source for the MOF formation was dissolved from the metal plate. The dissolved metal ions react with the ligand in the solvent and form a film on the metal plate. ${ }^{[1]}$ For cathodic deposition, both metal ions and ligand are dissolved in the solvent and probase formed from the reduction reaction near the conductive substrate. The formed probase facilitates the deprotonation of the metal-ligand complex and promotes the nucleation and crystal growth on the substrate ${ }^{[12]}$ For electrophoretic deposition, the charged particles are driven by the electrical field towards the conductive substrate and form a film on the substrate. In this method, a secondary growth is normally adopted to allow for further crystallization and defect healing. ${ }^{[13]}$ Organic solvents have been widely used for the film fabrication across the published works on electrochemical deposition. ${ }^{[9-10,}$ 12] Electrolyte such as methyltributylammonium methylsulfate (MTBS), tetrabutylammonium tetrafluoroborate (TBATFB), 1-butyl-3-methylimidazolium bromide (BMIN bromine), $\mathrm{NH}_{4} \mathrm{~F}, \mathrm{Na}_{2} \mathrm{SO}_{4}$, and $\mathrm{KCl}$ are normally added into the solvent to increase conductivity. ${ }^{[10]}$ Modulator was also sometimes added to modify the crystal morphology or speed up the crystallization for targeted film deposition. ${ }^{[14]}$ The addition of the electrolyte or modulator has somewhat added another dimension of complexity into the fabrication process. Little in-depth research was conducted so far to investigate the effects of the electrolyte or 


\section{WILEY-VCH}

1 modulator on the film fabrication. Considering the nature of the complicated reactions

2 happening during the deposition process, it would be much desirable if the addition of the

3 electrolyte can be eliminated for a better control over the synthesis process. Organic solvents

4 also cause a concern for the potential negative impacts on the environment in the large-scale

5 industrial production. In comparison, water would be the best possible choice for an

6 environmentally friendly process. ${ }^{[15]}$ However, as water is very easily to be electrolyzed in a

7 basic solution, it has remained to be a challenge in this field to adopt $100 \%$ water as the sole

8 solvent to anodically/cathodically deposit MOF membrane.

As a promising approach, research on electrochemical deposition of MOF is still at its infant stage with most of the efforts being focused on thin film production, ${ }^{[9-10]}$ only a few

11 works have been published for membrane fabrication. ${ }^{[12 b, 13]}$ The deposition procedure and

12 set-up are mostly delicately controlled such as careful selection of electrolyte and reference 13 electrode, using double electrolyte cell to eliminate the disturbance of the reactions occurred 14 on the counter electrode, and prolonged post-synthesis treatment, which makes this approach challenging to be used for scale-up production. In addition, little publication has used this approach to achieve satisfactory performance in gas separation with both high permeance and

17 selectivity. Here, we reported the fabrication of ZIF-8 membranes via aqueously cathodic deposition (ACD) without addition of any supporting electrolyte or modulator. The fabrication process used pure water as solvent and completed in only 60 min without any post-treatment. The membrane showed the best combination of permeance vs. selectivity in

21 the separation of $\mathrm{C}_{3} \mathrm{H}_{6} / \mathrm{C}_{3} \mathrm{H}_{8}$ mixture. 


\section{WILEY-VCH}

4

\section{Results and Discussions}

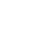

\subsection{Membrane Fabrication Set-up}

The experimental set-up is very simple. It comprises two electrodes in a single electrolyte cell, as shown in Figure 1. AAO coated with a conductive layer was used as the working electrode, while graphite paper without any pre-treatment was used as the counter electrode. In the deposition precursor solution, a relatively high ligand to $\mathrm{Zn}^{(\mathrm{II})}$ ratio of 60 was used for complete ligand deprotonation and thus to ensure a pure MOF to be formed. ${ }^{[16]}$ A dilute solution of $\mathrm{Zn}^{(\mathrm{II})}\left(\mathrm{Zn}^{(\mathrm{II})}: \mathrm{H}_{2} \mathrm{O}=1: 3889\right)$ was used to slow down the crystal growth in the bulk solution and thus help to form an uniform deposition on the substrate. During the deposition process, zinc cations were driven towards the substrate at cathode side and formed zinc-ligand complexes. The probase $\mathrm{OH}^{-}$released from the reduction of water built up a $\mathrm{OH}^{-}$ concentration gradient near the cathode. Thus, we hypothesized that the formed $\mathrm{OH}^{-}$, due to its higher $\mathrm{pKa}$ value compared with other species in the precursor, ${ }^{[17]}$ facilitated the deprotonation of the zinc-ligand complex near the substrate. The deprotonated zinc-ligand complex then further went to oligomerization, nucleation, crystallization and finally formed a layer of dense crystals on the substrate.

In this deposition process, due to the narrow potential window of water reduction (see Figure S2), the current density must be very low to avoid vehemently water electrolysis. Otherwise, the resulted hydrogen evolution will form a layer of bubbles on the substrate. The bubbling process would not only disrupt the deposition process, but also form very high concentration of $\mathrm{OH}^{-}\left(\left[\mathrm{OH}^{-}\right]\right)$near the substrate. The high $\left[\mathrm{OH}^{-}\right]$will corrode the already formed MOF, leading to severe amount of membrane defects. An optimal current density of $0.13 \mathrm{~mA} \mathrm{~cm}^{-2}$ was identified, which ensured both slow water electrolysis and quick deposition rate. After $60 \mathrm{~min}$, a uniform membrane with thickness in visible light wavelength range (See 


\section{WILEY-VCH}

1 Figure S3) was obtained. After the cathodic deposition, there was little precipitation obtained

2 in the residual solution, proving that most of MOFs grew directly on the substrate. As a 3 comparison, an in-situ growth of the membrane on AAO was also conducted, but no 4 membrane was formed (See Figure S4c and 4d).

\subsection{Membrane Growth}

An ex-situ investigation of the deposition process was conducted by SEM analysis (Figure 2 and Figure S5). The investigation was conducted at $10 \mathrm{~min}(\mathrm{M}-10), 20 \mathrm{~min}(\mathrm{M}-20), 30 \mathrm{~min}$ (M-30), 40 min (M-40) and $60 \mathrm{~min}$ (M-60). Looking at the whole process, the crystal size had

continuously increased from 10 min to 60 min (Figure $2 \mathrm{a}$-e), resulting in a gradual increase of membrane thickness (Figure 2f-j). Correspondingly, the membrane growth gradually decreased the conductivity of the substrate, which caused the increase of voltage in order to maintain the constant current (Figure S6). In this process, the crystal morphology gradually transformed from cubic (Figure 2a) to rhombic dodecahedra (Figure 2e) with mostly (110) phase exposed. The (110) phase is the most thermodynamically stable face of ZIF-8, ${ }^{[14 \mathrm{~b}]}$ ensuring the chemical stability of the membrane. Meanwhile, the thickness of the membrane was increased from $\sim 50 \mathrm{~nm}$ (Figure 2f) to $\sim 500 \mathrm{~nm}$ (Figure 2j).

At 10 min (Figure 2a), cubic crystals have been uniformly deposited on the solid surface around the pores of the substrate (See Figure S4a and $4 \mathrm{~b}$ for pristine AAO), implying that nucleation happened initially on the conductive surface. This phenomenon suggested that the electric current functioned as a driving force for the nucleation to occur. The corresponding XRD pattern (Figure S7) showed the characteristic peaks at (001), (002), (112), (022), (012), and (222) of ZIF-8 have emerged, suggesting the nucleation and crystallization have been co-happening within 10 min of the deposition. In addition, no foreign peaks were observed, suggesting a pure ZIF-8 phase was obtained. At 20 min (Figure 2b), the cubic 


\section{WILEY-VCH}

1 crystals have almost fully covered the substrate. When it went to $30 \mathrm{~min}$ (Figure 2c), the crystals have been undergoing a morphological transformation from cubic to rhombic dodecahedra, and intergrown to form a membrane on the substrate. For $30-40 \mathrm{~min}$, the crystals continued to crystallize and grew to seal the grain boundary via intergrowth (Figure 2d), and finally formed a continuous membrane at $60 \mathrm{~min}$ (Figure 2e). The final membrane formed comprised a single layer of crystals with size $\sim 500 \mathrm{~nm}$.

\subsection{Gas Separation Test}

The membranes deposited from 30 min onwards were tested for $\mathrm{C}_{3} \mathrm{H}_{6} / \mathrm{C}_{3} \mathrm{H}_{8}$ separation using

11 the Wicke - Kallenbach technique (Figure S8) with both sides of the membrane are maintained at ambient pressure. The feed is a mixture of 50:50 molar ratio of $\mathrm{C}_{3} \mathrm{H}_{6}$ and $\mathrm{C}_{3} \mathrm{H}_{8}$, while the permeate is purged with argon as a carrier gas. The results are listed in Table 1. As expected, the permeance of $\mathrm{C}_{3} \mathrm{H}_{6}$ decreased from $1618 \mathrm{GPU}\left(1 \mathrm{GPU}=3.35 \times 10^{-10} \mathrm{~mol} \mathrm{~m}^{-2} \mathrm{~s}^{-1}\right.$ $\left.\mathrm{Pa}^{-1}\right)$ to $692 \mathrm{GPU}$, while the selectivity slightly increased from 3 to 11 as the deposition went from $30 \mathrm{~min}$ to $40 \mathrm{~min}$. However, when it went from $40 \mathrm{~min}$ to $60 \mathrm{~min}$, the selectivity sharply enhanced to 142 with $\mathrm{C}_{3} \mathrm{H}_{6}$ permeance reached to $182 \mathrm{GPU}$. This observation suggests that the membrane had undergone an intense process of both crystal defect healing and grain boundary sealing in the last 20 min of deposition, which resulted in a continuous membrane exhibiting exceptional performance in $\mathrm{C}_{3} \mathrm{H}_{6} / \mathrm{C}_{3} \mathrm{H}_{8}$ separation. The selectivity of 142 has reached to the estimated ideal permselectivity of $130 .^{[5]}$ The permeance of 182 GPU has outperformed the majority of the published works while remained the selectivity uncompromised. Figure 3 shows the position of our work as compared with the published data. It is clear our results sit at the upper-right corner of the graph, highlighting the superior performance of our membrane. This also implies that the ACD developed in this work can be a promising approach for low-defect density MOF membrane fabrication. 


\section{WILEY-VCH}

The potential of ACD method to be used in real petrochemical industry was also evaluated. In general, the separation of $\mathrm{C}_{3} \mathrm{H}_{6} / \mathrm{C}_{3} \mathrm{H}_{8}$ is industrially carried out at temperature around $50{ }^{\circ} \mathrm{C}$ and pressure from 3 bar up to 18 bar. $^{[2]}$ Thus, both thermal and mechanical stability of the membrane are crucial for the real commercialization. To test the thermal stability, an online test of gas separation performance at varied temperatures $\left(22-130{ }^{\circ} \mathrm{C}\right)$ was conducted (Figure S9). With the increase of temperature, the permeance of $\mathrm{C}_{3} \mathrm{H}_{6}$ remained relatively stable, but the selectivity decreased and reached the lowest point at $130{ }^{\circ} \mathrm{C}$ (Figure S9a). This observation was mainly due to the increased $\mathrm{C}_{3} \mathrm{H}_{8}$ permanence (Figure S9b). The selectivity gradually returned to its original values after the temperature reduced back to around $22{ }^{\circ} \mathrm{C}$, implying that the membrane obtained by ACD method can withstand high temperatures without damaging its intrinsic crystalline structure. The selectivity at $50{ }^{\circ} \mathrm{C}$ and $130{ }^{\circ} \mathrm{C}$ are around 130 and 55 , both are satisfactory for industrial applications.

However, due to the weak mechanical strength of the AAO substrate, the membrane was tested at low pressure ( $\sim 1$ bar). To apply the membrane under higher pressures (e.g. 2-18 bar), the first requirement is to use stronger substrates. The ACD approach is feasible to prepare high quality ZIF- 8 membranes on strong substrates such as $\alpha$-alumina and metal flat plate or hollow fiber, as illustrated in Figure S10. The non-conductive $\alpha$-alumina substrates can be rendered conductive using the same way as we did for AAO substrates. The ACD approach also has potential to prepare ZIF-8 membrane on packed membrane modules since this approach only requires conductivity and are not sensitive to the substrate geometry. In particular, the defect 'self-healing' property of this approach will be very helpful to minimize the defect formation caused by substrate geometry, which is very beneficial for membrane assembly in different packed columns. Nevertheless, while the method can be potentially applied to stronger substrates, applying MOF membranes under high pressure is still a big 


\section{WILEY-VCH}

1 challenge that requires substantial future studies as demonstrate in many previous work in this 2 field.

\subsection{Discussion on Gas Separation Results}

The high permeance of our membrane can be attributed by three factors: (a) the membrane is ultra-thin $(\sim 500 \mathrm{~nm})$, allowing a short path for the gas to diffuse through; (b) the membrane has high porosity that can accommodate more gas molecules; (c) no detectable residual ligand existed in the structure which can block the pores of the crystal. Factor (a) has been proved in the SEM analysis (Figure 2j), showing the single layer of crystals of $\sim 500 \mathrm{~nm}$ solely contributed the thickness of the membrane. To prove factor (b), we conducted a krypton adsorption to measure the surface area of the membrane. This measurement has followed the previous published works. ${ }^{[18]}$ The Brunauer-Emmett-Teller (BET) specific surface area of M60, expressed as per membrane area per $100 \mathrm{~nm}$ thickness was $177 \mathrm{~m}^{2} \mathrm{~m}^{-2} 100 \mathrm{~nm}^{-1}$. This result was comparable with the published data using krypton adsorption (See Table S1). Considering the uncertainty of the data, the physisorption data was further evaluated by comparing the calculated surface area expressed as per gram of the membrane weight with the typical ZIF-8 surface area. The crystal density of ZIF-8 is $1.05-1.19 \mathrm{~g} \mathrm{~cm}^{-3}$ depending on the synthesis and activation methods, ${ }^{[19]}$ coupled with the obtained membrane thickness $\sim 500 \mathrm{~nm}$, the calculated BET surface area is $1485-1698 \mathrm{~m}^{2} \mathrm{~g}^{-1}$. It is noticeable that some crystals have grown into the pore of the AAO substrate (Figure 2), but no continuous growth of such crystals were observed along the near surface pores after careful analysis of a collection of SEM images. This didn't allow these 'in-pore' crystals to be accountable for the thickness of the membrane. It is aware that these crystals might affect the surface area calculated here. However, it was unable to quantify these crystals due to the limitation of the analysis technique. With this in mind, we suggest that the real BET surface area of the membrane 


\section{WILEY-VCH}

1 would be slightly lower that the calculated ideal surface area $\left(1485-1698 \mathrm{~m}^{2} \mathrm{~g}^{-1}\right)$.

2 Comparing the values with a broad of range of published data, ${ }^{[3,17,20]}$ this result was

3 considered to be within a reasonable range, which proves factor (b) that the membrane

4 exhibits high porosity.

To prove factor (c), FTIR measurement was conducted as shown in Figure 4.

6 Membrane obtained at $60 \mathrm{~min}$, and 2-methylimidazole (2-MIM) were plotted together for 7 comparison. Overall, C-H3 stretching mode at $2855 \mathrm{~cm}^{-1}, 2925 \mathrm{~cm}^{-1}$, and $2955 \mathrm{~cm}^{-1}$, and C-H aromatic stretching mode at $3135 \mathrm{~cm}^{-1}$ were observed for both samples. A particular finding was that the $\mathrm{N}-\mathrm{H}$ stretching band was observed in 2-MIM but disappeared in the membrane. This observation proves that almost all 2-MIM has been deprotonated and incorporated into the crystal structure, no FTIR detectable uncoordinated 2-MIM was existed in the membrane. The high selectivity of our membrane directly proves that our membrane has little defects. This can be further confirmed by the XPS studies as shown in Figure 5. Figure 5a and $5 b$ show $\mathrm{Zn} 2 \mathrm{p}$ and $\mathrm{N}$ 1s spectra of M-60, M-40 and M-30 respectively. For Zn 2p spectra, two peaks were observed for all the samples and assigned to $\mathrm{Zn} 2 \mathrm{p}_{3 / 2}$ for lower binding energy (BE) and $\mathrm{Zn} 2 \mathrm{p}_{1 / 2}$ for the higher BE. ${ }^{[21]}$ Clearly, M-60 displays two narrow peaks at 1022.1 $\mathrm{eV}$ and $1045.2 \mathrm{eV}$ respectively, which implies the majority of $\mathrm{Zn}$ are in the tetrahedral coordination. For the other two samples, a systematic peak shift and broadening towards lower BE, especially M-30, were observed. This could be closely correlated to the number of unsaturated $\mathrm{Zn}$ sites in the framework. It has been established that coordinately unsaturated sites interact more strongly with the adsorbed molecules (e.g. $\mathrm{ZnO}$ ) than the saturated metal sites, ${ }^{[22]}$ which would shift the peak towards lower BE. ${ }^{[23]}$ Similar observations were observed for $\mathrm{N}$ 1s spectra (Figure 5b), systematic peak shift and broadening towards lower BE were observed from sample M-60, M-40 and M-30. We didn't observe any peak above $400 \mathrm{eV}$ which is normally associated with $-\mathrm{NH}-$ of $2-\mathrm{MIM},{ }^{[24]}$ implying that little non- deprotonated 


\section{WILEY-VCH}

1 2-MIM was existed in our samples. This is also consistent with the FTIR results (Figure 4).

2 For M-60, a sharp peak was observed at $398.9 \mathrm{eV}$ which is assigned to N-Zn coordination,

3 suggesting that majority of $\mathrm{N}$ are in the similar chemical environment. For M-40 and M-30,

4 the peak shifted and broadened towards lower BE, we believe this phenomenon are also

5 mainly due to unsaturated $\mathrm{Zn}-\mathrm{N}$ bonds as the number ( $\mathrm{x}$ ) of $\mathrm{Zn}-\mathrm{N}_{\mathrm{x}}$ coordination is positively

6 correlated with BE. ${ }^{[24 b]}$ The unsaturated $\mathrm{Zn}$ is widely accepted as the point defects in the

7 framework and could significantly affect molecule diffusion. ${ }^{[25]}$ As the XPS results

8 demonstrated, M-30 exhibited the largest quantity of these defects. The defects were

9 continuously healed with the deposition time, which ended up with a low-defect density

10 membrane (M-60). This is in good agreement with the $\mathrm{C}_{3} \mathrm{H}_{6} / \mathrm{C}_{3} \mathrm{H}_{8}$ separation performance

11 discussed earlier.

\section{Conclusion}

In conclusion, we have developed an aqueously cathodic deposition (ACD) approach for ultra-facile fabrication of MOF membrane on AAO substrates without addition of any supporting electrolyte or modulator. This approach enables to fabricate ultra-thin membrane consisted of a single layer of crystals. A low-defect density membrane can be obtained within 60 min without any post-synthesis treatment. The membrane exhibited superior performance in $\mathrm{C}_{3} \mathrm{H}_{6} / \mathrm{C}_{3} \mathrm{H}_{8}$ separation with 182 GPU $\mathrm{C}_{3} \mathrm{H}_{6}$ permeance and 142 selectivity at room 21 temperature, making it outperform most of the published data. Notably, for the first time, this approach uses water as the sole solvent, adopts an extremely low current density, and employs a very simple apparatus set-up, enabling an attractive way for environmentally friendly, energy efficient and easily scalable MOF membrane fabrications. The membrane showed good thermal stability that well meets industrial application requirements. The selectivity decreased with temperature mainly due to the increase in propane permeance, but fully 


\section{WILEY-VCH}

1 recovered when the temperature reduced back to room temperature. The membrane could

2 only be tested under low pressure due to weak mechanical strength of the AAO substrate.

3 However, the ACD approach has the potential to fabricate high quality MOF membranes on

4 strong substrates such as $\alpha$-alumina and metal flat-sheet or hollow fiber. To apply the

5 membranes on high pressure gas separation, which is still a big challenge up to date, further

6 substantial research efforts will be needed.

7

\section{Experimental Section}

Chemicals and Materials: Zinc acetate dihydrate $\left(\mathrm{Zn}\left(\mathrm{CH}_{3} \mathrm{COO}\right)_{2} \cdot 2 \mathrm{H}_{2} \mathrm{O}\right.$, > 99\%) and potassium chloride $(\mathrm{KCl},>99 \%)$ were purchased from Sigma-Aldrich. 2-Methylimidazole $\left(\mathrm{C}_{4} \mathrm{H}_{6} \mathrm{~N}_{2}, 99 \%\right)$ was purchased from Acros Organics. All chemicals were used without further purification. The deionized water (DI water) used for synthesis was purified using Milli-Q ${ }^{\circledR}$ Academic ultrapure water system. Anodic aluminum oxide (AAO) substrates (Anodisc ${ }^{\mathrm{TM}} 13$ ) with pore size of $200 \mathrm{~nm}$ and thickness of $60 \mu \mathrm{m}$ were purchased from Whatman ${ }^{\circledR}$.

Preparation of Precursor Solution for Electrodeposition of ZIF-8 Membranes: 2Methylimidazole (4.105 g, $50 \mathrm{mmol})$ was dissolved in DI water $(50 \mathrm{~mL})$. In a separate container, $\mathrm{Zn}\left(\mathrm{CH}_{3} \mathrm{COO}\right)_{2} \cdot 2 \mathrm{H}_{2} \mathrm{O}(0.183 \mathrm{~g}, 0.83 \mathrm{mmol})$ was dissolved in DI water $(10 \mathrm{~mL})$. The two solutions were mixed together and stirred for 5 seconds to form the ZIF-8 precursor solution for the cathodic deposition.

\section{Cathodic Deposition of ZIF-8 Membranes on AAO Substrates: AAO substrates were coated} with platinum/palladium (Pt/Pd) via sputtering deposition at $20 \mathrm{~mA}$ for 20 seconds. The $\mathrm{Pt} / \mathrm{Pd}$-coated AAO substrate and a graphite paper were parallelly separated by $1.5 \mathrm{~cm}$ and immersed in the ZIF-8 precursor solution. The reaction was taken for $10 \mathrm{~min}, 20 \mathrm{~min}, 30 \mathrm{~min}$, $40 \mathrm{~min}$, and $60 \mathrm{~min}$ respectively under a current density of $0.13 \mathrm{~mA} \mathrm{~cm}^{-2}$. The resultant ZIF-8 


\section{WILEY-VCH}

1 membrane synthesized was thus named as M-10, M-20, M-30, M-40, and M-60 accordingly.

2 The membranes obtained were substantially rinsed by DI water and methanol after the reaction. The fabricated membranes were activated in methanol for gas permeation test.

Mixed-gas Permeation Test: The permeation test was performed by the Wicke-Kallenbach technique as shown in Figure S8. At the feed side, the equal molar ratio of $\mathrm{C}_{3} \mathrm{H}_{6} / \mathrm{C}_{3} \mathrm{H}_{8}$ with flow rate of $50 \mathrm{cc} \mathrm{min}^{-1}$ was introduced into the permeation cell. At the permeation side, argon was used as the sweep gas with flow rate of $50 \mathrm{cc} \mathrm{min}^{-1}$. Both sides were maintained at 1 bar using a pressure regulator. The composition of the permeate stream was analyzed online by Agilent 7890A gas chromatograph equipped with flame ionization detector (FID).

Material Characterization: Magellan ${ }^{\mathrm{TM}}$ XHR scanning electron microscope (SEM) was used to characterize the morphology of the membrane samples. The samples were coated with $\mathrm{Pt} / \mathrm{Pd}$ via sputtering deposition at $20 \mathrm{~mA}$ for 12 seconds. SEM imaging was conducted at an acceleration voltage of $3 \mathrm{kV}$.

X-ray diffraction (XRD) patterns were obtained using a D8 ADVANCE Twin X-ray diffractometer $(40 \mathrm{kV}, 40 \mathrm{~mA})$ with $\mathrm{Cu} \mathrm{K} \alpha$ radiation. The scanning was set to be $0.8 \mathrm{~s}$ per step from 5 to $40^{\circ} 2 \theta$ with a step size of $0.0085^{\circ} 2 \theta$.

Krypton physisorption isotherms were obtained at $77 \mathrm{~K}$ using a Micromeritics ASAP 2020 analyzer. Prior to physisorption measurement, the membrane samples were placed in an analysis tube and degassed under vacuum at $110{ }^{\circ} \mathrm{C}$ for 12 hours. The membrane BET surface area was measured by subtracting the BET surface area of the substrate.

A Nicolet 6700 Fourier-transform infrared (FT-IR) spectrometer with a KBr beam splitter and $\mathrm{CaF}_{2}$ window was used to obtain the IR spectra of the membranes. The membrane samples were degassed under vacuum at $110{ }^{\circ} \mathrm{C}$ for 12 hours before measurements. The samples were analyzed with 32 scans at a resolution of $0.964 \mathrm{~cm}^{-1}$. 


\section{WILEY-VCH}

Cyclic Voltammetry (CV) measurement was carried out using CHI660D

electrochemical workstation. $\mathrm{Pt} / \mathrm{Pd}$-coated $\mathrm{AAO}$ substrate, graphite paper and $\mathrm{Ag} / \mathrm{AgCl}$ (in 3

$\mathrm{M} \mathrm{KCl}$ aqueous solution) electrode were used as working electrode, counter electrode, and reference electrode respectively. $\mathrm{KCl}(100 \mathrm{mM})$ was used as supporting electrolyte for all the measurements. $\mathrm{CV}$ scans were measured at $100 \mathrm{mV} \mathrm{min}^{-1}$ from $-1.0 \mathrm{~V}$ to $1.2 \mathrm{~V}$.

X-ray photoelectron spectroscopy (XPS) measurements were conducted using a Kratos Amicus spectrometer with monochromatic Al-Ka radiation. A wide scan was acquired to calibrate the spectra before elemental scans. The binding energy (BE) was referenced at $284.6 \mathrm{eV}$ with C 1 s peak.

\section{Supporting Information}

Supporting Information is available from the Wiley Online Library or from the author.

\section{Conflict of Interest}

The authors declare no conflict of interest.

\section{Acknowledgements}

This work was supported by KAUST CRG Grant URF/1/3435. Ruicong Wei and Heng-Yu

Chi contributed equally to this work.

Received: ((will be filled in by the editorial staff))

Revised: ((will be filled in by the editorial staff)) Published online: ((will be filled in by the editorial staff))

\section{References}

[1] N. Rangnekar, N. Mittal, B. Elyassi, J. Caro, M. Tsapatsis, Chem. Soc. Rev. 2015, 44, 7128.

[2] Z. P. Lai, Curr. Opin. Chem. Eng. 2018, 20, 78.

[3] K. S. Park, Z. Ni, A. P. Côté, J. Y. Choi, R. Huang, F. J. Uribe-Romo, H. K. Chae, M. O’Keeffe, O. M. Yaghi, Proc. Nat. Acad. Sci. 2006, 103, 10186.

[4] K. Li, D. H. Olson, J. Seidel, T. J. Emge, H. Gong, H. Zeng, J. Li, J. Am. Chem. Soc. 2009, 131, 10368. 


\section{WILEY-VCH}

1 [5] C. Zhang, R. P. Lively, K. Zhang, J. R. Johnson, O. Karvan, W. J. Koros, J. Phys. Chem. Lett. 2012, 3, 2130.

[6] Y. Pan, T. Li, G. Lestari, Z. Lai, J. Membr. Sci. 2012, 390-391, 93.

[7] Y. Pan, W. Liu, Y. Zhao, C. Wang, Z. Lai, J. Membr. Sci. 2015, 493, 88.

[8] a) J. Liu, C. Wöll, Chem. Soc. Rev. 2017, 46, 5730; b) X. Ma, P. Kumar, N. Mittal, A. Khlyustova, P. Daoutidis, K. A. Mkhoyan, M. Tsapatsis, Science 2018, 361, 1008.

[9] W.-J. Li, M. Tu, R. Cao, R. A. Fischer, J. Mater. Chem. A 2016, 4, 12356.

[10] H. Al-Kutubi, J. Gascon, E. J. R. Sudhölter, L. Rassaei, ChemElectroChem 2015, 2, 462.

[11] R. Ameloot, L. Stappers, J. Fransaer, L. Alaerts, B. F. Sels, D. E. De Vos, Chem. Mater. 2009, 21, 2580.

[12] a) M. Li, M. Dincă, J. Am. Chem. Soc. 2011, 133, 12926; b) S. Zhou, Y. Wei, L. Li, Y. Duan, Q. Hou, L. Zhang, L.-X. Ding, J. Xue, H. Wang, J. Caro, Sci. Avd. 2018, 4.

[13] G. He, M. Dakhchoune, J. Zhao, S. Huang, K. V. Agrawal, Adv. Funct. Mater. 2018, $28,1707427$.

[14] a) I. Stassen, M. Styles, T. Van Assche, N. Campagnol, J. Fransaer, J. Denayer, J.-C. Tan, P. Falcaro, D. De Vos, R. Ameloot, Chem. Mater. 2015, 27, 1801; b) J. Cravillon, C. A. Schröder, H. Bux, A. Rothkirch, J. Caro, M. Wiebcke, CrystEngComm 2012, 14, 492.

[15] Y. Pan, Y. Liu, G. Zeng, L. Zhao, Z. P. Lai, Chem. Commun. 2011, 47, 2071.

[16] Y. Pan, Y. Liu, G. Zeng, L. Zhao, Z. Lai, Chem. Commun. 2011, 47, 2071.

[17] J. Cravillon, R. Nayuk, S. Springer, A. Feldhoff, K. Huber, M. Wiebcke, Chem. Mater. $2011,23,2130$.

[18] a) I. Stassen, M. Styles, G. Grenci, Hans V. Gorp, W. Vanderlinden, Steven D. Feyter, P. Falcaro, D. D. Vos, P. Vereecken, R. Ameloot, Nat. Mater. 2015, 15, 304; b) Q. Zhang, Z. Wu, Y. Lv, Y. Li, Y. Zhao, R. Zhang, Y. Xiao, X. Shi, D. Zhang, R. Hua, J. 


\section{WILEY-VCH}

Yao, J. Guo, R. Huang, Y. Cui, Z. Kang, S. Goswami, L. Robison, K. Song, X. Li, Y. Han, L. Chi, O. K. Farha, G. Lu, Angew. Chem. Int. Ed. 2019, 58, 1123.

[19] T. Tian, J. Velazquez-Garcia, T. D. Bennett, D. Fairen-Jimenez, J. Mater. Chem. A 2015, 3, 2999.

[20] a) K. Zhou, B. Mousavi, Z. Luo, S. Phatanasri, S. Chaemchuen, F. Verpoort, J. Mater. Chem. A 2017, 5, 952; b) V. V. Butova, A. P. Budnyk, E. A. Bulanova, C. Lamberti, A. V. Soldatov, Solid State Sci. 2017, 69, 13.

[21] P. Druska, U. Steinike, V. Šepelák, J. Solid State Chem. 1999, 146, 13.

[22] H. Chen, L. Wang, J. Yang, R. T. Yang, J. Phys. Chem. C 2013, 117, 7565.

[23] a) H. Lee, S. C. Park, J. S. Roh, G. H. Moon, J. E. Shin, Y. S. Kang, H. B. Park, J. Mater. Chem. A 2017, 5, 22500; b) M. Wang, L. Jiang, E. J. Kim, S. H. Hahn, RSC Adv. 2015, 5, 87496.

[24] a) S. Kabir, K. Artyushkova, B. Kiefer, P. Atanassov, Phys. Chem. Chem. Phys. 2015, 17, 17785; b) I. Matanovic, K. Artyushkova, M. B. Strand, M. J. Dzara, S. Pylypenko, P. Atanassov, J. Phys. Chem. C 2016, 120, 29225.

[25] a) C. Zhang, C. Han, D. S. Sholl, J. R. Schmidt, J. Phys. Chem. Lett. 2016, 7, 459; b) D. S. Sholl, R. P. Lively, J. Phys. Chem. Lett. 2015, 6, 3437. 


\section{WILEY-VCH}
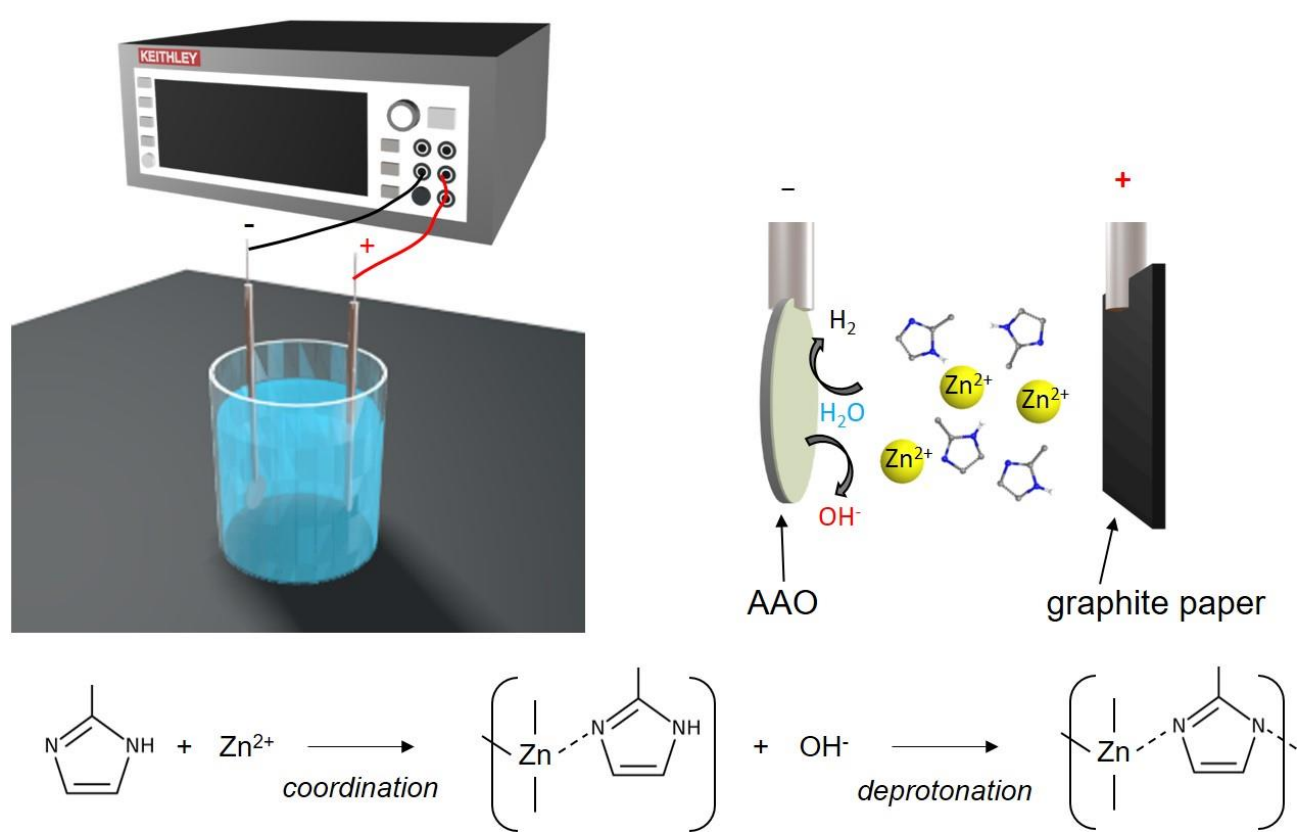

Figure 1. Illustration of experimental setup used for aqueously cathodic deposition (ACD) of ZIF-8 membrane.

4

5

6

7

8

9

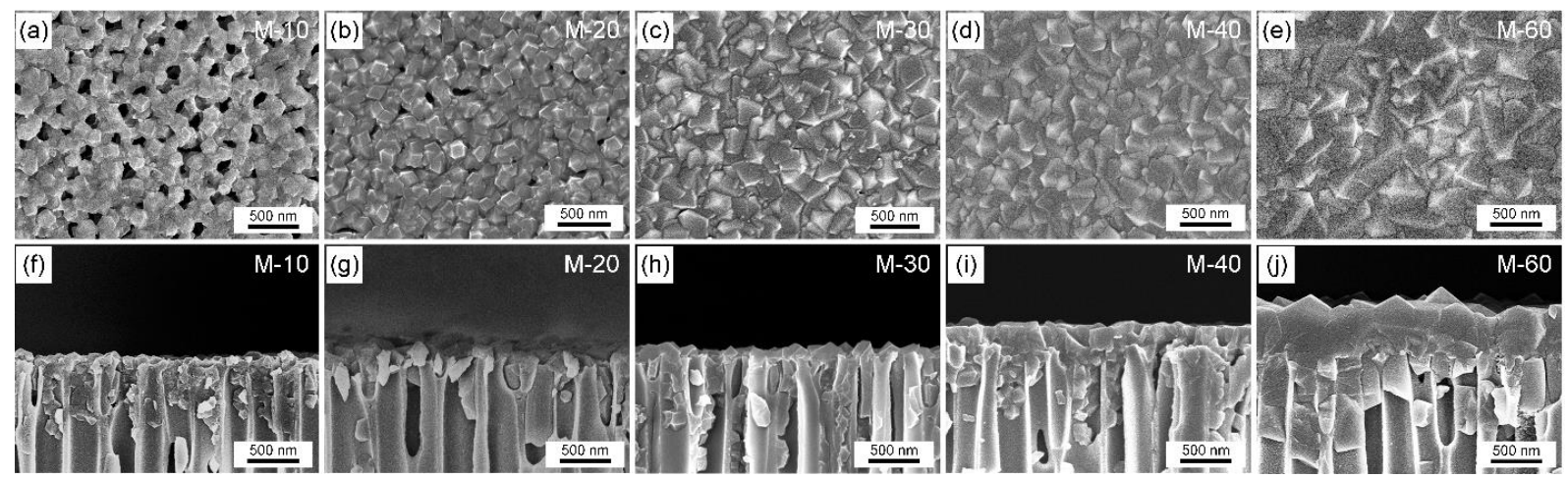

11

Figure 2. SEM images of front and cross-section of membranes synthesized at: (a,f) $10 \mathrm{~min}$, 12 13

(b,g) $20 \mathrm{~min},(\mathrm{c}, \mathrm{h}) 30 \mathrm{~min},(\mathrm{~d}, \mathrm{i}) 40 \mathrm{~min}$, and (e,j) $60 \mathrm{~min}$. 
WILEY-VCH

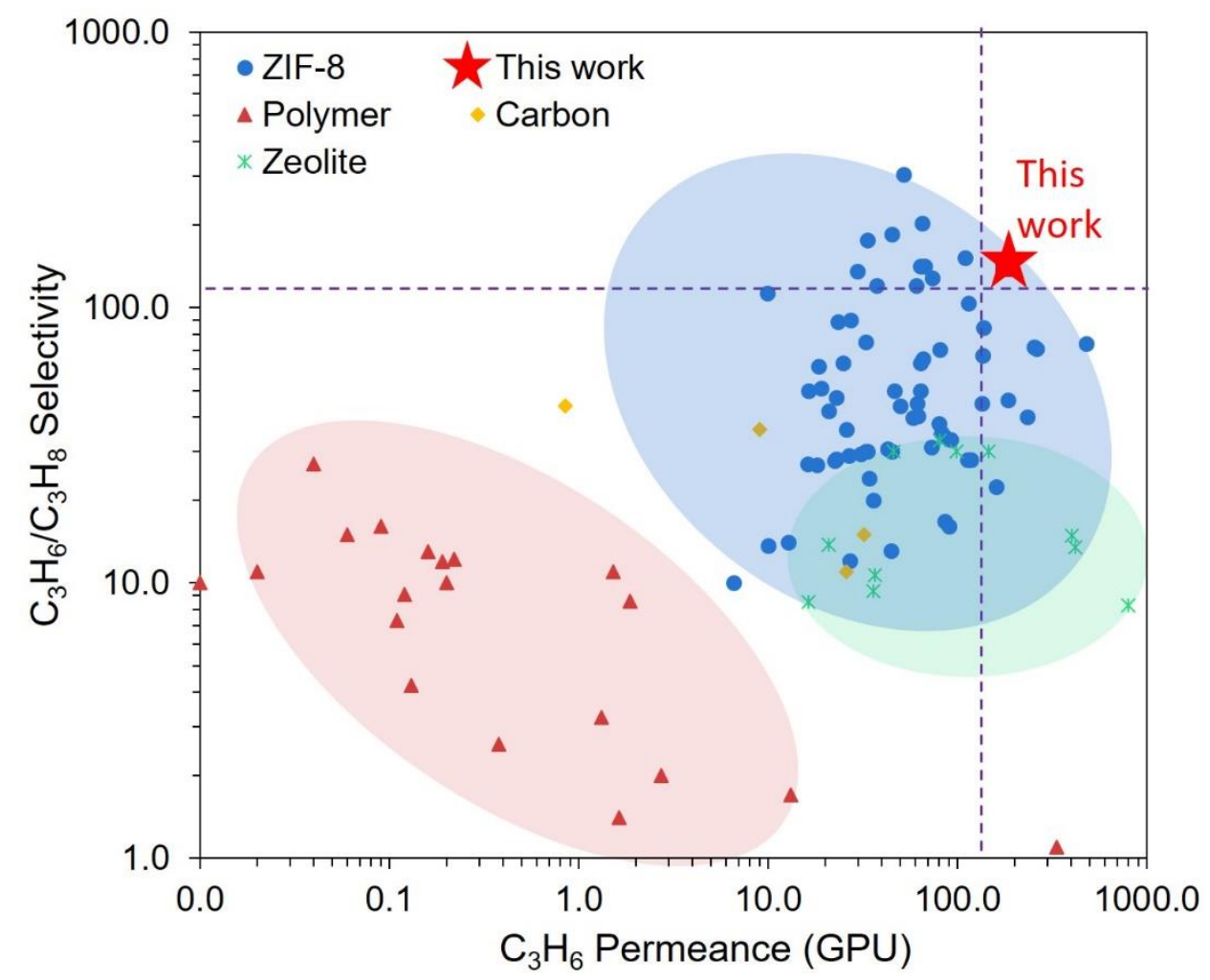

2

Figure 3. Comparison of $\mathrm{C}_{3} \mathrm{H}_{6} / \mathrm{C}_{3} \mathrm{H}_{8}$ separation performance with membranes reported up to 2019.

6

7

8

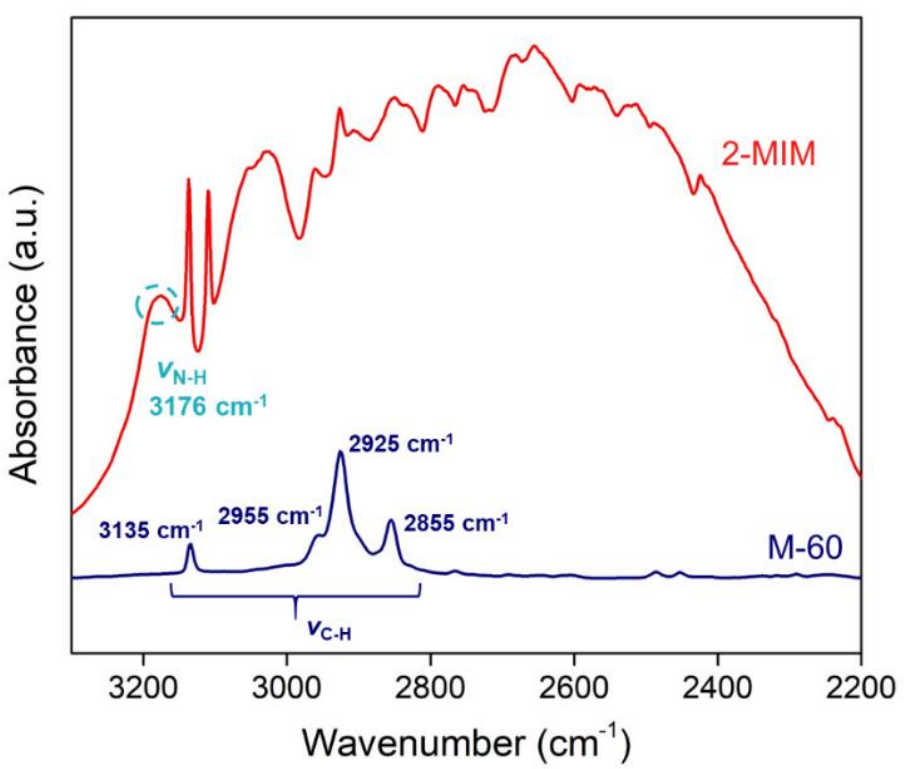

10 Figure 4. Comparison of FTIR spectra of M-60 with 2-MIM. 


\section{WILEY-VCH}
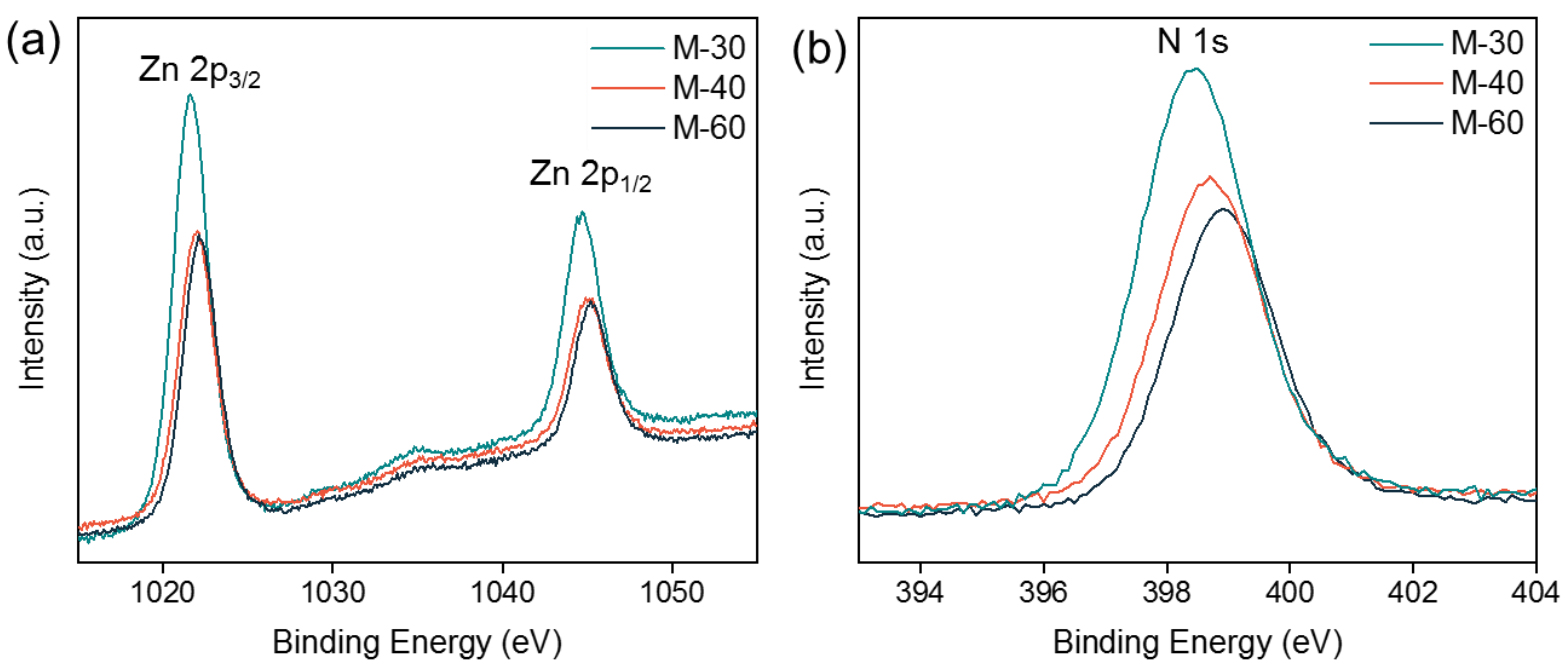

2 Figure 5. XPS spectra of (a) Zn 2p and (b) N 1s.

3

4

5

6

7

8

9

\begin{tabular}{ccc}
\hline Sample & $\mathrm{C}_{3} \mathrm{H}_{6}$ Permeance (GPU) & $\mathrm{C}_{3} \mathrm{H}_{6} / \mathrm{C}_{3} \mathrm{H}_{8}$ Selectivity \\
\hline M-30 & $1618 \pm 22$ & $3 \pm 0.03$ \\
M-40 & $692 \pm 17$ & $11 \pm 0.39$ \\
M-60 & $182 \pm 9$ & $142 \pm 4$ \\
\hline
\end{tabular}

10

11 


\section{WILEY-VCH}

\section{Table of Content}

An ultrathin ZIF-8 membrane with $\sim 500 \mathrm{~nm}$ thickness is fabricated via a novel aqueously cathodic deposition (ACD) method. The membrane shows superior $\mathrm{C}_{3} \mathrm{H}_{6} / \mathrm{C}_{3} \mathrm{H}_{8}$ separation performance with the permeance of $\mathrm{C}_{3} \mathrm{H}_{6}$ up to $182 \mathrm{GPU}$ and the selectivity of $\mathrm{C}_{3} \mathrm{H}_{6}$ over $\mathrm{C}_{3} \mathrm{H}_{8}$ up to 142 , which surpass all the reported membrane performances prepared by conventional methods.

\section{Metal-Organic Frameworks}

R. Wei ${ }^{\dagger}$, H.-Y. Chi ${ }^{\dagger}$, X. Li, D. Lu, Y. Wan, C.-W. Yang, Z. Lai*

Aqueously Cathodic Deposition of ZIF-8 membranes for Superior Propylene/propane

\section{Separation}

15

16

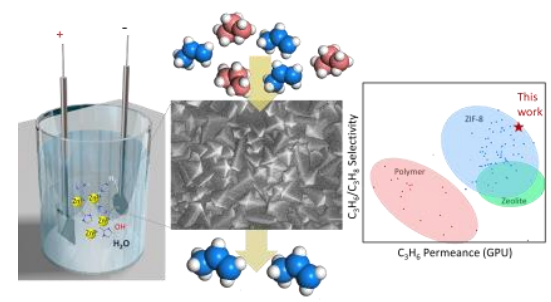

17 